\title{
HIV prevalence, risky behaviors, and discrimination experiences among transgender women in Cambodia: descriptive findings from a national integrated biological and behavioral survey
}

Siyan $\mathrm{Yi}^{1}{ }^{12^{*}}$, Chanrith Ngin ${ }^{1}$, Sovannary Tuot ${ }^{2}$, Pheak Chhoun ${ }^{1}$, Srean Chhim³ ${ }^{3}$ Khuondyla Pal ${ }^{1}$, Phalkun Mun ${ }^{4}$ and Gitau Mburu ${ }^{5}$

\begin{abstract}
Background: Transgender people are disproportionately affected by HIV. Despite their high vulnerability to HIV, lack of adequate epidemiological and surveillance data related to this population in many countries prevents provision of appropriate services. This paper summarizes descriptive findings from a national integrated biological and behavioral survey and discusses policy implications of the findings on HIV prevention among transgender women in Cambodia.
\end{abstract}

Methods: This cross-sectional study was conducted between December 2015 and February 2016. Participants were recruited from 20 sites in the capital city and 12 provinces of Cambodia using Respondent Driven Sampling (RDS) method. Behavioral data were collected through structured questionnaire interviews, and rapid finger-prick HIV testing was performed. Descriptive data analyses were conducted using STATA.

Results: This study included 1,375 transgender women with a mean age of 25.9 years $(S D=7.1)$. The overall prevalence of HIV was 5.9\%. The prevalence of HIV was significantly higher among urban participants compared to their rural counterparts (6.5 vs. $2.6 \%, p=0.02$ ). Almost one in five (19.6\%) had never been tested for HIV prior to the study. Overall, $45.0 \%$ reported ever using gender affirming hormones. More than one-third (39.1\%) reported not using condoms in their last sex, 29.8\% had engaged in sex in exchange for money/gifts, and $14.0 \%$ reported that they had experienced at least one symptom of sexually transmitted infections (STI) in the past year. About one in ten (10.1\%) reported having used some form of amphetamine-type stimulant drugs, while 6.5\% reported having sex during or after using illicit drugs. A significant number of participants experienced sexual abuse (39.2\%), losing a job (24.3\%), or physical abuse (23.6\%) because of their transgender identity. In addition, 82.9 and $88.9 \%$ would be willing to use the HIV self-test and pre-exposure prophylaxis (PrEP), respectively, if they become available.

Conclusions: The high prevalence of HIV, STI, and related risk behaviors among transgender women in Cambodia is of great concern, suggesting an urgent need to further expand tailored prevention interventions for this key population focusing on individual, social, and structural drivers of HIV. HIV self-test and PrEP should be explored as a priority.

Keywords: HIV, Sexually transmitted infections (STI), HIV prevention, Transgender women, Sexual behaviors, Cambodia

\footnotetext{
* Correspondence: siyan@doctor.com

${ }^{1}$ KHANA Center for Population Health Research, No. 33, Street 71, Tonle Bassac, Chamkar Mon, Phnom Penh, Cambodia

${ }^{2}$ Center for Global Health Research, Touro University California, Vallejo, USA

Full list of author information is available at the end of the article
} 


\section{Background}

Transgender people are disproportionately affected by HIV. The term "transgender" refers to a diverse range of people whose gender identities differ from the sex assigned to them at birth $[1,2]$. A recent review by Baral et al. shows that transgender women have a pooled HIV prevalence of $19.1 \%$ [3], which is a 49 -fold increased odds of HIV infection compared with non-transgender adults of reproductive age [2].

An increasing amount of epidemiological research has highlighted factors that increase HIV vulnerability among transgender people. Gender-based sexual violence that transgender people experience due to their gender identity [4] increases risk of HIV infection [5]. Stigma prevents access to HIV services and care [6], and is often associated with inconsistent condom use in anal intercourse and sex work among transgender women $[7,8]$. Coinfection with perianal and other sexually transmitted infections (STI) could also facilitate acquisition and transmission of $\operatorname{HIV}[2,9]$. In addition, recent studies suggest ways in which gender affirming hormone use could impact HIV vulnerability [2]. Furthermore, sex work is often associated with higher prevalence of HIV among transgender people [10].

Whereas evidence showing the high vulnerability to HIV of this population is increasing, transgender people are generally underserved in national HIV responses [11]. For instance, the majority of countries do not include transgender in the national HIV plans and strategies [3]. This is often confounded by lack of adequate data related to transgender people in many countries [2]. Population-based representative studies and routine surveillance among transgender people are generally limited globally [12]. In addition, there is a paucity of data to guide clinical care of transgender people on antiretroviral and gender-affirming hormone therapies [13]. Furthermore, transgender people are often subsumed under men who have sex with men (MSM) in many countries [11, 14], which makes it difficult to provide tailored responses to their behaviors and vulnerabilities distinct from those of MSM [7, 11]. As a result, HIV programs are not effective for this population [7].

Research and dissemination of findings related to transgender people are required to inform policy and programming for these particularly vulnerable people. In this article, we present descriptive findings from a largescale national integrated biological and behavioral survey among transgender women in Cambodia.

\section{Methods}

\section{Study design, settings, and participants}

The cross-sectional study was conducted between December 2015 and February 2016 in 13 major sites (1 capital city and 12 provinces) of Cambodia. Respondent
Driven Sampling (RDS) method was used to recruit participants with support from community-based implementing partners of KHANA, the largest national NGO providing community-based HIV prevention, care, and support services in Cambodia [15]. Among the 13 study sites, participants were recruited in 20 specific locations (six locations in Phnom Penh and 14 locations in the provinces). The number of the selected locations was determined based on the proportion of the required sample size in each study site, and the estimated population of transgender women in each site. Eligible participants were individuals who: (1) were biologically male at birth and self-identified as a woman, (2) were aged 18 years or over, (3) reported having sex with at least one man in the past 12 months, (5) could speak Khmer, and (6) were able and willing to provide written consent to participate in the study.

Four initial seeds were identified at each site by outreach workers from KHANA's implementing partners based on age (two seeds aged 18 to 24 and the other two seeds aged 25 or older). These seeds had to meet the eligibility criteria for participation and have an established and large social network comprising about 10 or more other transgender women in their given location. Eligibility to participate as a seed was determined by the leader of data collection team using a paper-based eligibility form. Each seed was given three coupons and asked to refer three additional transgender women. US\$2 was given to each seed for a successful referral. Each seed was expected to extend to 3-6 "recruitment waves" in each site. If the initial seeds did not recruit participants or if enrollment was halted because all recruitment chains had "dried up" (i.e. stopped recruiting), additional seeds were selected based on the above criteria. In total, 80 seeds were selected by the implementing partners' outreach workers initially.

\section{Data collection and training}

Data were collected by two teams with eight personnel each that included one field supervisor, five interviewers, one lab technician, and one counselor from the Provincial AIDS and STI Program. The field supervisor conducted eligibility screening of the participants. Each consenting participant was assigned a unique personal identification number, which was used to link all data collected from each participant. The unique personal identification number was not linked with any personal data to protect confidentiality. The counsellor then explained objectives of the study in details, including the process of HIV testing, potential risks and benefits of participation, and obtained written informed consent. This was followed by HIV counselling conducted by the counsellor, and HIV testing conducted by the lab technician. Finger-prick-based HIV testing was conducted using Determine ${ }^{\mathrm{TM}}$ test, according to 
the national protocol [16]. HIV testing and counseling were performed in accordance with all applicable national guidelines.

After the HIV test was conducted, an interviewer administered the questionnaire in a private room using an Android tablet. At the end of the interview, the counsellor provided the HIV test result and post-test counselling. Participants with a reactive result were referred to the nearest HIV clinic for a confirmatory test, and were invited to come back to the implementing partner site for ongoing support and follow-up services. The field supervisor then provided a coupon incentive to the participants. Each participant received US\$4 in cash to compensate for their time, and a package of three condoms. This amount of incentive was determined reasonable and equivalent to a typical meal for one person and the cost of transportation.

Prior to data collection, all interviewers and field supervisors were trained for three days on data collection methods and tool pretesting and reflection, to safeguard consistency, quality, and validity of the data. The training included interview techniques, confidentiality, and privacy, and provided opportunities for the study team the opportunity to rehearse questionnaire administration and other study procedures. During data collection, review sessions with interviewers were conducted regularly to review progress and communicate any problems or issues which required solving.

\section{Variables and measures}

The questionnaire was developed using standardized and validated tools adapted from previous literature, the most recent Cambodia Demographic and Health Survey, and other studies among HIV key populations in Cambodia. It was initially developed in English and then translated into Khmer, the national language of Cambodia. Another translator then back-translated it into English to ensure that the "content and spirit" of every original item was maintained. Clear instructions and explanations were included to avoid any confusion during the interviews.

To design the study and develop the tools, consultative meetings were held with representatives of transgender women, community people, non-governmental organizations (NGOs), donor agencies, government officers, as well as researchers and practitioners working on HIV and AIDS in Cambodia. Prior to data collection, the questionnaire was pretested to ensure that the wording and contents of the questionnaire were culturally suitable, acceptable, and clearly understood by the study participants before it was finalized. In the pilot study, we conducted face-to-face interviews with 20 transgender women recruited from Phnom Penh to assess the contents, format, length, language, and appropriateness of the questionnaire. Necessary modifications were made based upon feedbacks from the pilot study and from the consultative meetings. The final version of the questionnaire was used for the main data collection.

The questionnaire collected the following information: (1) Socio-demographic characteristics; (2) transgender identity and related experiences; (3) sexual behaviors and condom use in different relationships; (4) accessibility to condoms and lubricants; (5) HIV/STI screening and care seeking behaviors; (6) substance use (alcohol, illicit drugs); and (7) experiences of stigma and discrimination in communities and health facilities.

\section{Data management and analyses}

Data from the questionnaires collected via Android tablets were transferred onto a secure server after completion of each day of data collection. After synchronization, the data were cleared from the tablet. At the conclusion of the two-month data-collection, the data were downloaded from the secure server, tabulated, and transcribed into a Microsoft Excel format. Data were then imported into STATA (Version 12.0) for analyses. Prior to the analyses, data were weighted to account for the effect of RDS method. Descriptive analyses were conducted to calculate the counts and proportion (\%) for categorical variables and means with standard deviations (SD) for continuous variables. Where applicable, Chi-square test or Student's $t$-test was used to compare between groups.

\section{Ethical considerations}

Participants were required to provide written consent after being informed in details about the study objectives, risk, and benefits. Participants were informed that they could withdraw from the study at any time. Interviews and HIV testing and counseling were conducted at private locations within drop-in centers, private houses, or offices of KHANA's implementing partners, and confidentiality was ensured by assigning a personal identity number (PIN) to each participant and removing all personal identifiers. The study protocol was approved by the National Ethics Committee for Health Research (NECHR) of the Ministry of Health, Cambodia (No. 420 NECHR) and FHI 360's Protection of Human Subjects Committee (PHSC No. 713897).

\section{Results}

\section{Characteristics of the study participants}

Characteristics of the study participants are shown in Table 1 . Of the 1,375 participants, majority (83.4\%) were urban dwelling, and $53.0 \%$ were younger than 25 years old. Mean age of the respondents was 25.9 years $(\mathrm{SD}=$ 7.1). Two-thirds of the participants (68.6\%) completed high school, and $9.1 \%$ had higher education. Common occupations of the participants were hair dressers/ 
Table 1 Descriptive characteristics of the study participants

\begin{tabular}{|c|c|}
\hline Variables & Number (\%) \\
\hline \multicolumn{2}{|l|}{ Community types } \\
\hline Urban & $1146(83.4)$ \\
\hline Rural & $229(16.6)$ \\
\hline \multicolumn{2}{|l|}{ Age groups } \\
\hline $18-24$ & $729(53.0)$ \\
\hline $25-34$ & $503(36.6)$ \\
\hline $35-44$ & $99(7.2)$ \\
\hline$\geq 45$ & $44(3.2)$ \\
\hline \multicolumn{2}{|l|}{ Current marital status } \\
\hline Married & $7(0.5)$ \\
\hline Widowed/divorced/separated & $18(1.3)$ \\
\hline Never married & $1334(97.2)$ \\
\hline Refuse to answer & $16(1.2)$ \\
\hline \multicolumn{2}{|l|}{ Formal education attained } \\
\hline Primary (0-6 years) & $307(22.3)$ \\
\hline High school (7-12 years) & $943(68.6)$ \\
\hline Higher education (>12 years) & $125(9.1)$ \\
\hline \multicolumn{2}{|l|}{ Main occupations } \\
\hline Unemployed & $64(4.7)$ \\
\hline Hair dresser/beautician & $482(35.1)$ \\
\hline Office worker (government/private company staff) & $50(3.6)$ \\
\hline Labor/farmer & $241(17.5)$ \\
\hline Seller & 149 (10.8) \\
\hline Entertainment worker & $203(14.8)$ \\
\hline Student & $108(7.9)$ \\
\hline NGO staff & $34(2.5)$ \\
\hline Other & $44(3.2)$ \\
\hline \multicolumn{2}{|l|}{ Average monthly income in past six months (USD) } \\
\hline$<100$ & $351(25.6)$ \\
\hline $100-199$ & $530(38.6)$ \\
\hline $200-299$ & $266(19.3)$ \\
\hline$\geq 300$ & $226(16.5)$ \\
\hline
\end{tabular}

Abbreviations: NGO, non-governmental organization; USD, United States dollar; $I Q R$, interquartile range

beauticians $(35.1 \%)$, laborers/farmers (17.5\%), and entertainment workers (14.8\%). More than one-third of the participants (38.6\%) reported their average monthly income in the past six months of US\$ 100-199, while $16.5 \%$ reported it to be more than US\$ 300 .

\section{HIV prevalence}

The overall prevalence of HIV was $5.9 \%(n=81)$; of whom, $52 \%(n=42)$ were not aware of their HIV status prior to the study. The highest prevalence of HIV was found among transgender women in Banteay Meanchey (11.7\%) and Siem Reap (11.3\%), followed by Phnom
Penh (6.5\%) and Battambang (5.3\%). Similar HIV prevalence rates were found in Kampong Speu (4.3\%), Tbong Khmum (4.2\%), and Kandal (4.2\%). No HIV-positive cases were detected in Koh Kong, Prey Veng, and Svay Rieng (Fig. 1). The prevalence of HIV was significantly higher among transgender women living in urban communities than among those living in rural communities (6.5 vs. $2.6 \%, p=0.02$ ). The highest prevalence of HIV was found among transgender women in the age group of 35-44 years old (13.1\%), followed by those in the age group of $>45$ years old (11.4\%). Transgender women in the age group of younger than 25 years old had the lowest $\mathrm{HV}$ prevalence rate at $3.0 \%$.

\section{Gender identity and affirming hormone use}

Table 2 shows that $42.2 \%$ of the participants identified themselves as female, while $57.2 \%$ identified as third gender. In the Cambodian context, "third gender" refers to transgender people (women or men). This term is now considered discriminating and unspecific; and it thus is not recommended for use in HIV or other related programs. About half of them (48.0\%) reported dressing up as a woman all the time. Of total, $45.0 \%$ reported ever used hormone or other substances for beauty purposes such as pills (45.0\%), injection (18.3\%), and skin patches (14.0\%). The injections were mostly reported to be performed by skilled personnel (67.8\%), followed by non-skilled personnel (25.7\%), and self-injection (6.5\%). Of those who have injected the substances, $1.5 \%$ reported ever sharing needles while injecting the substances, and 9.2\% had ever had an operation to change any part of their body to become more feminine.

\section{Sexual behaviors}

As shown in Table 3, 8.5\% reported ever had sex with a woman in their lifetime, and $2.2 \%$ reported ever had sex with a woman in the past 12 months. Of those who engaged in intercourse with a woman in the past 12 months, $66.7 \%$ reported having sex not in exchange for money, and $33.3 \%$ reported both in exchange and not in exchange for money.

Table 3 shows information about participants' sexual experiences with men. Nearly all respondents (97.9\%) have had sexual intercourse with a man. The majority $(87.5 \%)$ reported a receptive role, while only $2.2 \%$ reported an insertive role, and $10.3 \%$ reported both roles. In the past three months, $86.0 \%$ had anal sex with a man, of which $61.9 \%$ used condom in their last sex. Among all participants, $81.6 \%$ had sex not in exchange for money/gifts, of which $62.1 \%$ reported not always using condoms in the past three months by giving the reasons that they were in relationship (62.8\%); their partners were not HIV/STI infected (31.0\%); no condom was available (27.1\%); they felt better without condom 


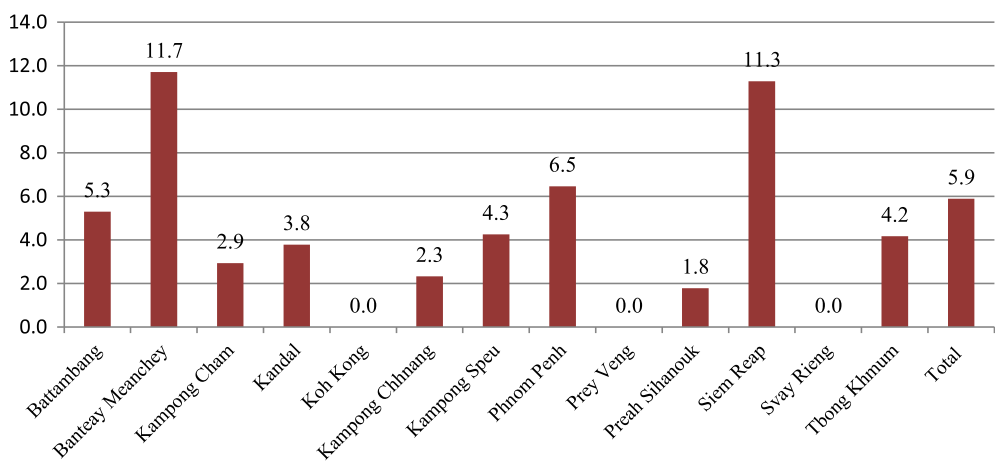

Fig. 1 Prevalence of HIV among the study participants by study site

(20.9\%); and their partners refused to use it (17.1\%). Among all participants, $29.8 \%$ had sex in exchange for money/gifts, of which $40.0 \%$ reported not always using condoms in the past three months by giving the reasons that no condom was available (39.8\%); they were in relationship (32.6\%); their partners refused to use it (29.8\%); and they felt better without condom (21.6\%).

\section{Access to condoms and lubricants}

Figure 2 shows the access to condoms and lubricant in the past 12 months. The most commonly reported sources of condoms and lubricant were friends/outreach workers $(71.8$ and $70.6 \%$ for condoms and lubricant, respectively), followed by pharmacies/drug

Table 2 Gender identity and hormone use experiences of the study participants

\begin{tabular}{ll}
\hline Variables & Number (\%) \\
\hline Self-identified & $580(42.2)$ \\
Female & $786(57.2)$ \\
Third gender & $8(0.6)$ \\
Uncertain & \\
Frequency of dressing up as a woman & $660(48.0)$ \\
All the time & $715(52.0)$ \\
Not all the time & $618(45.0)$ \\
Ever used hormone/non-hormone substances & $561(40.8)$ \\
$\quad$ Pill & $252(18.3)$ \\
Injection & $192(14.0)$ \\
Skin patches & $17(6.5)$ \\
How hormone/non-hormone substance hormone were injected \\
$\quad$ Self-injection & $177(67.8)$ \\
Injected by skilled personnel & $67(25.7)$ \\
Injected by non-skilled personnel & $20(3.2)$ \\
Ever shared needles when injecting beauty substances & $127(9.2)$ \\
Ever had operation to change any parts of your body & \\
to become a woman &
\end{tabular}

Abbreviations: NGO, non-governmental organization stores/clinics (43.9 and 39.0\% for condoms and lubricant, respectively).

\section{STI symptoms and treatment}

Table 4 shows the experiences of STI symptoms and treatment seeking behaviors among transgender women in this study. Of the total survey sample, $14.0 \%$ reported that they had experienced at least one STI symptom in the past 12 months. The most commonly reported symptoms were symptoms on the anus (6.1\%). Of those with the symptoms, 138 (71.1\%) reported seeking treatment for their most recent symptom from an NGO facility $(21.5 \%)$, private pharmacy $(16.4 \%)$, public facility (16.4\%), and private facility (14.9\%).

\section{HIV testing, treatment, and willingness to use PrEP}

Table 5 shows that $19.6 \%$ had never been tested for HIV before, while $44.3 \%$ had been tested within the past 6 months. Of those who had been tested and received results, 3.6\% reported being HIV positive. Among those who reported being HIV positive, $94.9 \%$ were currently on ART. Majority of the testing (69.7\%) were done at an NGO facility.

Many participants (82.9\%) said they were willing to use the HIV self-test if it were available. When asked if they had ever heard of pre-exposure prophylaxis (PrEP), 37.6\% participants answered 'Yes.' Regarding the likeliness of using PrEP, $88.9 \%$ said they would likely use it and that they would prefer to access the PrEP at a local NGO (53.5\%) over other locations (Table 5).

\section{Substance use}

Table 6 depicts the reported alcohol and illicit drug use among transgender women in this study. Of total, 75.9\% reported drinking at least one can of beer or a glass of wine in the past 3 months. More than half (56.1\%) responded that this occurred less than once a month, while $8.1 \%$ responded four or more times a week. Of total, $10.1 \%$ reported having used some form of amphetamine-type stimulants (Yama, Crystal Ice, Ecstasy), while 
Table 3 Sexual behaviors of the study participants with biological women and men

\begin{tabular}{ll}
\hline Sexual behaviors & Number (\%) \\
\hline Ever had sex with a woman (lifetime) & $117(8.5)$ \\
Ever had sex with a woman in the past 12 months & $30(25.6)$ \\
Type of female sexual partners in the past 12 months & \\
Female commercial partners & $0(0.0)$ \\
Female non-commercial partners & $20(66.7)$ \\
Both (commercial/non-commercial) & $10(33.3)$ \\
Role in anal sex with a man & \\
$\quad$ Insertive & $29(2.2)$ \\
Receptive & $1145(87.5)$ \\
Both & $135(10.3)$ \\
Had anal sex with a man, past 3 months & $1183(86.0)$ \\
Median number of male partners in past 3 months (IQR) & $3(1-7)$ \\
Used condom at last anal sex & $732(61.9)$ \\
Anal sex with male non-commercial partners in past & $1122(85.7)$ \\
3 months & $3(1-5)$ \\
Median number of male non-commercial partners in &
\end{tabular}
past 3 months (IQR)

Condom use in anal sex with male non-commercial partner in past 3 months

$\begin{array}{ll}\text { Not always } & 697(62.1) \\ \text { Always } & 425(37.9)\end{array}$

Reason for not using condoms with male non-commercial partner in the past 3 months

$\begin{array}{ll}\text { We are in a relationship } & 438(62.8) \\ \text { He/she is not HIV/STI infected } & 216(31.0) \\ \text { Too high to use condom } & 37(5.3) \\ \text { No condom available } & 189(27.1) \\ \text { Feel better without condom } & 146(20.9) \\ \text { I am HIV-infected } & 2(0.3) \\ \text { I penetrated, so I am not at risk } & 4(0.6) \\ \text { Partner refused } & 119(17.1) \\ \text { Other } & 11(1.6) \\ \text { Had sex with a male commercial partner in the past } & 410(29.8) \\ \text { 12 months } & 3(1-8) \\ \text { Median number of male commercial partners in the } & \end{array}$
past 3 months (IQR)

Condom use with male commercial partners in the past 3 months

$\begin{array}{ll}\text { Not always } & 164(40.0) \\ \text { Always } & 246(60.0)\end{array}$

Reasons for not using condoms with male commercial partners

We are in a relationship

She is not HIV/STI infected

Too high to use condom

No condom available

Feel better without condom
Table 3 Sexual behaviors of the study participants with biological women and men (Continued)

\begin{tabular}{ll}
\hline I penetrated, so I am not at risk & $1(0.6)$ \\
Partner refused & $54(29.8)$ \\
Other & $7(2.2)$ \\
\hline
\end{tabular}

Abbreviation: HIV, human immunodeficiency virus; IQR, interquartile range; STI, sexually transmitted infection

$0.9 \%$ reported having used other drugs (marijuana, heroin, etc.). Of total, $1.5 \%$ reported having injected some form of illicit drugs in the past 3 months, and $6.5 \%$ reported having sex during or after using illicit drugs.

\section{Discrimination experiences}

Figure 3 shows the discrimination experienced by transgender women in this study because of their transgender identity or gender presentation. Of total, $42.1 \%$ experienced problems getting a job, whereas $24.3 \%$ experienced problems losing a job. The next most common discrimination experienced was sexual abuse or assault (39.2\%), while the least common form of discrimination reported in this study were problems getting services from an HIV prevention program (8.5\%) and had problems getting health or medical services (9.1\%).

\section{Discussion}

There is growing interest in understanding the epidemiology of HIV among transgender people. This study set out to explore demographic, behavioral and health-related characteristics of transgender women in Cambodia. Results showed that the prevalence of HIV was $5.9 \%$ among the sample. In addition, the results provide useful data on high-risk sexual behaviors, STI symptoms, substance use, HIV testing, discrimination experiences, and willingness to use PrEP among this population.

The HIV prevalence found in our study is slightly higher than the $4.2 \%$ found by a recent study by Weissman et al. [17], but both are significantly higher than an earlier study conducted in 2010 which found a prevalence of $2.6 \%$ among transgender women [18]. However, direct comparison of findings from this study with those in the previous ones is difficult because of the differences in characteristics of the samples and measures. Our study was conducted in 13 sites (one city and 12 provinces), while the study by Weissman et al. was conducted in six sites [17] and the Bros Khmer study in seven sites [18]. The timeframes used to measure key variables, such as HIV testing and condom use, were also not consistent. Studies from Cambodia have consistently reported higher levels of HIV prevalence among transgender people compared to MSM [17, 18], underscoring the importance of separating transgender people 


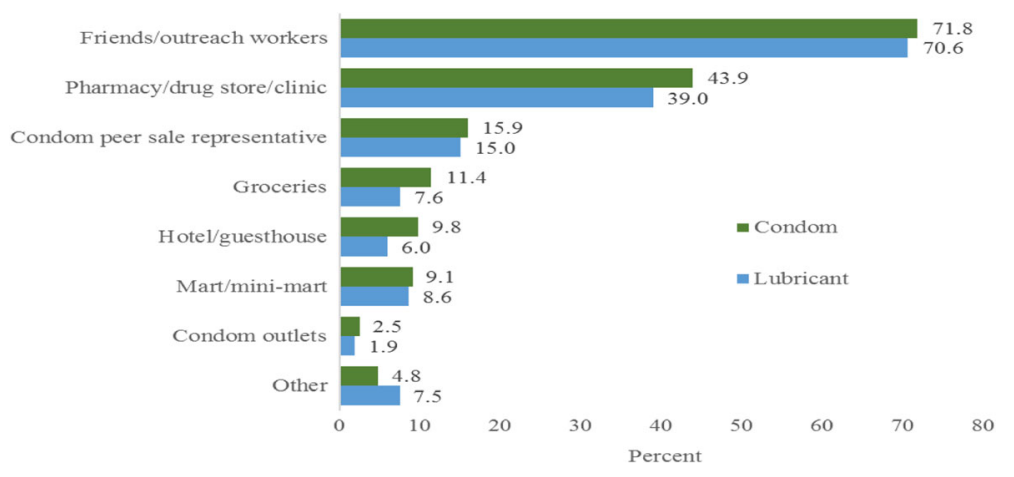

Fig. 2 Access to condoms and lubricant by type of facility in the past 12 months

from MSM so as to have an accurate picture of HIV epidemic among this group.

Since 2013, transgender women have been recognized as a separate population from MSM within the Standard Operating Procedures of Boosted Continuum of Prevention, Care and Treatment [19]. However, even within transgender people, differences were noted in HIV prevalence based on residence. The prevalence was significantly higher among transgender women in urban communities compared to those in rural areas, which suggests the need to better focus on cities and urban areas. These findings also buttress calls for geographic localization of HIV prevention efforts [10], given that HIV rates were much higher in Banteay Meanchey, Siem Reap, Phnom Penh, and Battambang provinces compared to other provinces.

An important implication from the study was related to combination prevention. The majority of the participants were sexually active, with $97.9 \%$ reporting having

Table 4 STI symptoms and treatment experiences of the study participants

\begin{tabular}{ll}
\hline Variables & Number (\%) \\
\hline STI symptoms experienced in the past 12 months & $193(14.0)$ \\
Cut or sores in the genital area & $46(3.4)$ \\
Swelling in the genital area & $16(1.2)$ \\
Abnormal urethral discharge & $36(2.6)$ \\
Symptoms on the anus & $84(6.1)$ \\
Symptom in the mouth/throat & $39(2.8)$ \\
Facility where treatment for the most recent STI symptoms & \\
was received & \\
Did not seek treatment & $57(29.2)$ \\
Private pharmacy & $32(16.4)$ \\
Private facility & $29(14.9)$ \\
Public facility & $32(16.4)$ \\
NGO facility & $42(21.5)$ \\
Traditional healer & $3(1.5)$ \\
\hline
\end{tabular}

Abbreviations: NGO, non-governmental organization; STI, sexually transmitted infection intercourse with men, mostly anal sex. However, a significant number of these did not use condoms consistently. Given the high prevalence of HIV in this group, these findings suggest that expansion of HIV prevention interventions for this group is warranted. This is particularly relevant given that two thirds of the participants

Table 5 HIV testing experience, status awareness, and willingness to use PrEP

\begin{tabular}{ll}
\hline Variables & Number (\%) \\
\hline Ever been tested for HIV & $269(19.6)$ \\
Never & $431(31.4)$ \\
1-3 months & $178(12.9)$ \\
$4-6$ months & $346(25.1)$ \\
$7-12$ months & $151(11.0)$ \\
$>12$ months ago & $1079(97.5)$ \\
Received results from the last HIV test & $37(94.9)$ \\
Currently on ART & \\
Place of the most recent HIV test & $119(10.8)$ \\
Private facilities & $208(18.8)$ \\
Public facilities & $771(69.7)$ \\
NGO facilities/community based HIV testing & $9(0.8)$ \\
Other & $842(82.9)$ \\
Willingness to use HIV self-test if it were available & $359(37.6)$ \\
Ever heard of Pre-exposure prophylaxis (PrEP) & \\
Likeliness of using PrEP & $79(8.3)$ \\
Unlikely & $849(88.9)$ \\
Likely & $27(2.8)$ \\
Not sure & \\
Preferred place to access PrEP if available & $511(53.5)$ \\
Local NGOs & $148(15.5)$ \\
ART clinic & $270(28.3)$ \\
Pharmacy & $(2.7)$ \\
\hline Other & \\
\hline
\end{tabular}

Abbreviations: $A R T$, antiretroviral therapy; $H I V$, human immunodeficiency virus; $N G O$, non-governmental organization; $\operatorname{PrEP}$, pre-exposure prophylaxis 
Table 6 Substance use among the study participants

\begin{tabular}{ll}
\hline Variables & Number (\%) \\
\hline Drank at least one can of beer or glass of wine in & $1042(75.9)$ \\
the past 3 months & \\
$\begin{array}{l}\text { Frequency of having more than } 5 \text { drinks in one day } \\
\text { in the past } 3 \text { months }\end{array}$ & $336(24.4)$ \\
$\quad$ Never more than five drinks & $771(56.1)$ \\
Less than once a month & $157(11.4)$ \\
$1-3$ times a week & $111(8.1)$ \\
4 or more times a week & $1224(89.0)$ \\
Ever used illicit drugs in the past 12 months & $139(10.1)$ \\
Never & $12(0.9)$ \\
Yes, ATS (Yama, crystal ice, ecstasy) & $20(1.5)$ \\
Other drugs (marijuana, heroin, etc.) & $89(6.5)$ \\
Ever injected any illicit drugs in the past 3 months & \\
Ever had sex during/after using illicit drugs in the \\
past 3 months
\end{tabular}

Abbreviation: ATS, Amphetamine-type stimulants

had not heard of PrEP, but $88.9 \%$ were willing to use it. Combined with the high proportion (94.9\%) of HIV positive participants who were on ART, these findings suggest that provision of PrEP could reduce incidence of HIV among this population. The high prevalence of sex work in exchange of money among this sample provides another reason to consider PrEP for transgender sex workers. Other studies have highlighted the heightened vulnerability and the needs for better tailored interventions for transgender sex workers [20, 21].

The low rate of HIV testing observed among transgender women in this study is of concern and suggests that significant effort is required to increase HIV testing uptake. In particular, HIV education and benefit of HIV testing should be widely promoted among this population. The lack of HIV awareness could influence HIV sexual behaviors, including the use of condoms, or commercial sex [22]. In addition, HIV testing is the first step towards early access to treatment, which also has high preventive benefits. Results from this study indicate that participants were willing to consider HIV self-testing, which could provide additional flexibility in access to testing. HIV self-testing has potential to reach individuals who are least likely to seek testing in a public clinic, hospital, voluntary confidential counseling and testing center (VCCT), or with a community-based nongovernmental organization. Results from other settings indicate that self-testing may be acceptable to transgender people [23] and should be made available while considering issues related to confirmation and linkage to care, cost [24], quality assurance, as well as support needs of different potential users of self-tests [25].

Our study indicates that $6.5 \%$ of the participants reported having sex during or after using illicit drugs, so called "Chem sex", which may increase sexual risk taking $[26,27]$. Furthermore, $45 \%$ of the participants had ever used gender affirming hormones, which included through injections in $18 \%$ of the cases. Our results also indicate that the injecting practices were often unsafe (by selfinjection or non-skilled providers) and included sharing of needles. Therefore, HIV prevention efforts should explore provision of PrEP and education regarding the use of drugs during sex, while considering how safe needle exchange interventions can be integrated for those who inject drugs or hormones.

Our study shows the importance of community-based outreach services in increasing access to HIV prevention services. Peers and outreach workers were the sources of condoms for $70 \%$ of the participants. In addition, findings related to STI suggested that the majority of the participants that experienced STI symptoms shunned public facilities as a source of treatment, with the majority seeking health care from NGO or private facilities and pharmacies. Furthermore, the majority of participants accessed HIV testing from community-based NGOs. These preferences may be related to the demand

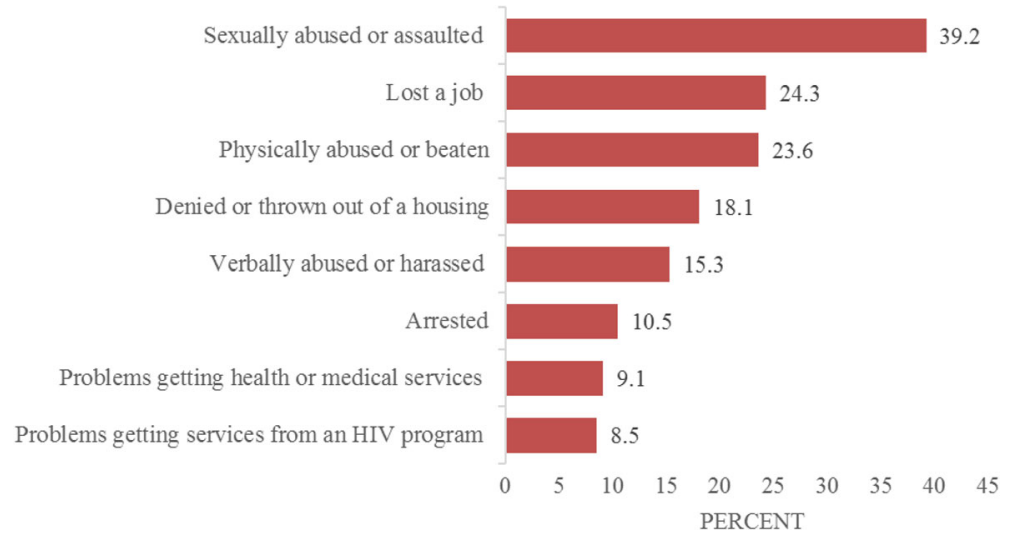

Fig. 3 Discrimination experiences of the study participants 
creation, peer-support building or less stigmatizing nature of community-based organizations and services in the study context. Evidence from other contexts indicate that when services, often community-based, are nonstigmatizing, gender-affirming, trans-specific and leveraged on local peers and resources, transgender people access them [28-30].

Conversely, these findings highlight a need to better understand how the capacity of public health facilities to provide friendly services to transgender people can be strengthened. In 2014, the World Health Organization released a global guidance on HIV programming for key populations, including transgender people [31]. More recently, implementation tools developed to assist the provision of comprehensive community-led responses for transgender people have been launched [32]. In Cambodia, these guidelines and implementation tools need to be adapted and implemented.

Stigma and discrimination are powerful drivers of inequitable access to HIV and health services among transgender [6,33] and other [34] populations. Yet HIV cannot be eliminated unless transgender persons can have universal access to HIV and health services. Our study shows that a significant number of transgender women experienced discrimination based on their transgender identity, including problems getting services from an HIV prevention program (8.5\%) and other health and medical services $(9.1 \%)$. In a similar Cambodian study, $54.8 \%$ of participants reported having experienced discrimination related to transgender identity in their lifetime [17]. Consequently, significant effort will be required to sensitize, and train health care providers so that they provide appropriate care with non-judgmental attitudes to transgender women. General practitioners, nurses and non-clinical health professionals working in public hospitals and HIV clinics need to be equipped with appropriate clinical skills including clerking, counselling, and examination skills so as to provide appropriate care to transgender women. This is particularly important because $39.2 \%$ of the participants reported experiencing sexual abuse or assault, which can increase HIV vulnerability and requires access to health and medical services.

More broadly, the intersectionality of multiple deleterious determinants of health, including drug use or abuse, violence or stigmatization, poor mental health, internalized transphobia, and economic hardships may potentiate HIV vulnerability [35], reduce uptake of services [34], and contribute to poor HIV treatment outcomes [2] among different populations, including transgender people. Hence, multi-sectoral interventions to mitigate these complex interacting syndemic factors in an integrated fashion are required. Importantly, this approach should include sectors beyond physical health, such as mental health, legal, policing, and social protection sectors, to mitigate arbitrary arrests $[6,36]$, lack of employment [37], criminalization, victimization [38], violence [5, 38], and other structural drivers of vulnerability to HIV among this population.

Findings from this study should be cautiously interpreted in light of the design, recruitment, methods of data collection, and sample profile. As this was a crosssectional study, it captures a snapshot view of the population studied, and may not document changes in measured variables over time. Our study sample had relatively educated participants, which may not be representative of all transgender women in the country, and were initially recruited from those who had some contact with outreach workers. Future studies should be more cautious about selecting seeds that are more representative of sub-populations of transgender women by considering their socio-demographic characteristics such as education levels, occupations, incomes, etc. Sexual behaviors and other sensitive information were collected from the participants through a self-reported questionnaire, which is often at high risk of bias [39]. Despite these limitations, this paper provides important information that can be built upon to inform programming and policy.

\section{Conclusions}

There is a growing interest in understanding the epidemiology of HIV among transgender people. This article presents findings from a cross-sectional study among transgender women in Cambodia, showing the high HIV prevalence and risky sexual behaviors among the participants. These findings call for an urgent need to further expand and refine prevention interventions for transgender women, focusing on individual, social, and structural domains of vulnerability. This study therefore should inform policy and programmatic interventions to promote health and prevent the HIV vulnerability among transgender people in Cambodia.

\section{Abbreviations \\ AIDS: Acquired immune deficiency syndrome; ART: Antiretroviral therapy; HIV: Human immunodeficiency virus; IQR: Interquartile range; MSM: Men who have sex with men; NGO: Non-governmental organization; PIN: Personal identification number; PrEP: Pre-exposure prophylaxis; RDS: Respondent driven sampling; SD: Standard deviation; STI: Sexually transmitted infections; TG: Transgender; USD: United States dollar; VCCT: Voluntary confidential counseling and testing center}

\section{Acknowledgements}

This study was financially supported by the United States President's Emergency Plan for AIDS Relief (PEPFAR)/the United States Agency for International Development (USAID) through HIV/AIDS Flagship Project. We thank all data collection team members, KHANA's implementing partners, community support volunteers, outreach workers, and all participants for their excellent contribution to this study. Disclaimer: Content of this paper is the responsibility of the authors and does not reflect the view of USAID or our respective institutions. 


\section{Funding}

This study was funded by the United States President's Emergency Plan for AIDS Relief (PEPFAR)/the United States Agency for International Development (USAID)

\section{Availability of data and materials}

The data used for this study cannot be made available in the manuscript, the supplemental files, or a public repository due to the ethical restriction stated in the agreement with the National Ethics Committee for Health Research. However, they can be accessed upon request from the Principal Investigator (Dr. Siyan Yi) at siyan@doctor.com.

\section{Authors' contributions}

SY developed the research question, analyzed the data, wrote the manuscript, and interpreted the results. SY, ST, PC, SC, and PM designed the study, developed the research protocol and tools. PC, SC, and KP were responsible for trainings and data collection. CN and GB supported data analyses and manuscript writing All authors assisted in the interpretation of the results, contributed to the writing, and approved the final manuscript.

\section{Authors' information}

SY (PhD) is Director; CN (PhD) is Senior Research Advisor; PC (MPH) and PK (MHSc) are Research Fellow; ST (MA) is Research Manager at KHANA Center for Population Health Research in Cambodia. SC (MHSc) is Senior Research Officer at FHI 360 in Cambodia; PM (MPH) is Chief of Surveillance Unit, National Center for HIV/AIDS, Dermatology and STD; GM (MPH) is a PhD candidate at Division of Health Research, Lancaster University, UK.

\section{Competing interests}

The authors declare that they have no competing interests.

\section{Consent for publication}

Consent to publish was obtained from participants as stated in the informed consent form.

\section{Ethics approval and consent to participate}

The study protocol was approved by the National Ethics Committee for Health Research (NECHR) of the Ministry of Health, Cambodia (No. 420 NECHR) and FHI 360's Protection of Human Subjects Committee (PHSC No. 713897). A written informed consent was obtained from each participant.

\section{Publisher's Note}

Springer Nature remains neutral with regard to jurisdictional claims in published maps and institutional affiliations.

\section{Author details \\ ${ }^{1}$ KHANA Center for Population Health Research, No. 33, Street 71, Tonle Bassac, Chamkar Mon, Phnom Penh, Cambodia. ${ }^{2}$ Center for Global Health Research, Touro University California, Vallejo, USA. ${ }^{3} \mathrm{FHI}$ 360, Phnom Penh, Cambodia. ${ }^{4}$ National Center for HIV/AIDS, Dermatology and STD (NCHADS), Phnom Penh, Cambodia. ${ }^{5}$ Division of Health Research, Lancaster University, Lancaster, UK.}

Received: 14 November 2016 Accepted: 16 May 2017 Published online: 23 May 2017

\section{References}

1. Joint United Nations Programme on HIV/AIDS (UNAIDS). UNAIDS terminology guidelines. Geneva: Joint United Nations Programme on HIV/AIDS (UNAIDS); 2011.

2. Poteat T, Scheim A, Xavier J, Reisner S, Baral S. Global Epidemiology of HIV Infection and Related Syndemics Affecting Transgender People. J Acquir Immune Defic Syndr. 2016;72 Suppl 3:S210-9.

3. Baral SD, Poteat T, Stromdahl S, Wirtz AL, Guadamuz TE, Beyrer C. Worldwide burden of HIV in transgender women: a systematic review and meta-analysis. Lancet Infect Dis. 2013;13(3):214-22.

4. Kaplan RL, McGowan J, Wagner GJ. HIV prevalence and demographic determinants of condomless receptive anal intercourse among trans feminine individuals in Beirut, Lebanon. J Int AIDS Soc. 2016;19(3 Suppl 2):20787.

5. Brennan J, Kuhns LM, Johnson AK, Belzer M, Wilson EC, Garofalo R. Syndemic theory and HIV-related risk among young transgender women: the role of multiple, co-occurring health problems and social marginalization. Am J Public Health. 2012;102(9):1751-7.
6. Scheim Al, Santos GM, Arreola S, Makofane K, Do TD, Hebert P, et al. Inequities in access to HIV prevention services for transgender men: results of a global survey of men who have sex with men. J Int AIDS Soc. 2016;19(3 Suppl 2):20779.

7. Stahlman S, Liestman B, Ketende S, Kouanda S, Ky-Zerbo O, Lougue M, et al. Characterizing the HIV risks and potential pathways to HIV infection among transgender women in Cote d'lvoire, Togo and Burkina Faso. J Int AIDS Soc. 2016;19(3 Suppl 2):20774

8. de Lind van Wijngaarden JW, Schunter BT, Iqbal Q. Sexual abuse, social stigma and HIV vulnerability among young feminised men in Lahore and Karachi, Pakistan. Cult Health Sex. 2013;15(1):73-84.

9. Veronese V, van Gemert C, Bulu S, Kwarteng T, Bergari I, Badman S, et al. Sexually transmitted infections among transgender people and men who have sex with men in Port Vila, Vanuatu. Western Pac Surveill Response J. 2015;6(1):55-9.

10. UNAIDS. The GAP Report. Geneva: United Nations Programme on HIV/AIDS (UNAIDS); 2014

11. Poteat TC, Keatley J, Wilcher R, Schwenke C. Evidence for action: a call for the global HIV response to address the needs of transgender populations. J Int AIDS Soc. 2016;19(3 Suppl 2):21193.

12. Reisner SL, Poteat T, Keatley J, Cabral M, Mothopeng T, Dunham E, et al Global health burden and needs of transgender populations: a review. Lancet. 2016:388(10042):412-36.

13. Radix A, Sevelius J, Deutsch MB. Transgender women, hormonal therapy and HIV treatment: a comprehensive review of the literature and recommendations for best practices. J Int AIDS Soc. 2016;19(3 Suppl 2):20810.

14. Poteat T, German D, Flynn C. The conflation of gender and sex: Gaps and opportunities in HIV data among transgender women and MSM. Glob Public Health. 2016;11(7-8):835-48.

15. Yi S, Chhoun P, Brant S, Kita K, Tuot S. The Sustainable Action against HIV and AIDS in Communities (SAHACOM): Impacts on health and quality of life of people living with HIV in Cambodia. Glob J Med Public Health. 2014;3(5):1-12.

16. National Center for HIV/AIDS DaS. Standard Operating Procedures for HIV Testing and Counseling (HTC). Phnom Penh: National Center for HIV/AIDS, Dermatology and STD (NCHADS); 2012.

17. Weissman A, Ngak S, Srean C, Sansothy N, Mills S, Ferradini L. HIV Prevalence and Risks Associated with HIV Infection among Transgender Individuals in Cambodia. PLoS One. 2016;11(4):e0152906.

18. Liu K, Chhea C. The BROS Khmer: Behavioral risks on-site serosurvey among at-risk urban men in Cambodia. Phnom Penh: Family Health International; 2010.

19. National Center for HIV/AIDS, Dermatology and STD. Boosted continuum from prevention to care and treatment. Phnom Penh: NCHADS; 2013.

20. Poteat T, Wirtz AL, Radix A, Borquez A, Silva-Santisteban A, Deutsch MB, et al. HIV risk and preventive interventions in transgender women sex workers. Lancet. 2015;385(9964):274-86.

21. Bianchi FT, Reisen CA, Zea MC, Vidal-Ortiz S, Gonzales FA, Betancourt F, et al Sex work among men who have sex with men and transgender women in Bogota. Arch Sex Behav. 2014;43(8):1637-50.

22. Zea MC, Reisen CA, del Rio-Gonzalez AM, Bianchi FT, Ramirez-Valles J, Poppen PJ. HIV Prevalence and Awareness of Positive Serostatus Among Men Who Have Sex With Men and Transgender Women in Bogota, Colombia. Am J Public Health. 2015;105(8):1588-95

23. Lippman SA, Moran L, Sevelius J, Castillo LS, Ventura A, Treves-Kagan S, et al. Acceptability and Feasibility of HIV Self-Testing Among Transgender Women in San Francisco: A Mixed Methods Pilot Study. AIDS Behav. 2016;20(4):928-38.

24. Bustamante MJ, Konda KA, Joseph Davey D, Leon SR, Calvo GM, Salvatierra J et al. HIV self-testing in Peru: questionable availability, high acceptability but potential low linkage to care among men who have sex with men and transgender women. Int J STD AIDS. 2016. (In press).

25. Greacen T, Kersaudy-Rahib D, Le Gall JM, Lydie N, Ghosn J, Champenois K. Comparing the Information and Support Needs of Different Population Groups in Preparation for 2015 Government Approval for HIV Self-testing in France. PLoS One. 2016;11(3):e0152567.

26. Bracchi M, Stuart D, Castles R, Khoo S, Back D, Boffito M. Increasing use of 'party drugs' in people living with HIV on antiretrovirals: a concern for patient safety. AIDS. 2015;29(13):1585-92.

27. Bourne A, Reid D, Hickson F, Torres-Rueda S, Weatherburn P. Illicit drug use in sexual settings ('chemsex') and HIV/STI transmission risk behaviour among gay men in South London: findings from a qualitative study. Sex Transm Infect. 2015; 91(8):564-8.

28. Reisner SL, Bradford J, Hopwood R, Gonzalez A, Makadon H, Todisco D, et al. Comprehensive transgender healthcare: the gender affirming clinical and public health model of Fenway Health. J Urban Health. 2015;92(3):584-92. 
29. Reback CJ, Ferlito D, Kisler KA, Fletcher JB. Recruiting, Linking, and Retaining High-risk Transgender Women into HIV Prevention and Care Services: An Overview of Barriers, Strategies, and Lessons Learned. Int J Transgend. 2015;16(4):209-21.

30. Shaikh S, Mburu G, Arumugam V, Mattipalli N, Aher A, Mehta S, et al. Empowering communities and strengthening systems to improve transgender health: outcomes from the Pehchan programme in India. J Int AIDS Soc. 2016; 19(3 Suppl 2):20809.

31. World Health Organization. Consolidated guidelines on HIV prevention, diagnosis, treatment and care for key populations. Geneva: World Health Organization; 2014.

32. Wolf RC, Adams D, Dayton R, Verster A, Wong J, Romero M, et al. Putting the $t$ in tools: a roadmap for implementation of new global and regional transgender guidance. J Int AIDS Soc. 2016;19(3 Suppl 2):20801.

33. Poteat T, Reisner SL, Radix A. HIV epidemics among transgender women. Curr Opin HIV AIDS. 2014;9(2):168-73.

34. Mburu G, Ram M, Siu G, Bitira D, Skovdal M, Holland P. Intersectionality of HIV stigma and masculinity in eastern Uganda: implications for involving men in HIV programmes. BMC Public Health. 2014;14:1061.

35. Operario D, Nemoto T. HIV in transgender communities: syndemic dynamics and a need for multicomponent interventions. J Acquir Immune Defic Syndr. 2010:55 Suppl 2:S91-3.

36. Schneiders ML, Weissman A. Determining barriers to creating an enabling environment in Cambodia: results from a baseline study with key populations and police. J Int AIDS Soc. 2016;19(4 Suppl 3):20878.

37. Raiford JL, Hall GJ, Taylor RD, Bimbi DS, Parsons JT. The Role of Structura Barriers in Risky Sexual Behavior, Victimization and Readiness to Change HIV/STI-Related Risk Behavior Among Transgender Women. AIDS Behav. 2016;20(10):2212-21.

38. Chakrapani V, Newman PA, Shunmugam M, Logie CH, Samuel M. Syndemics of depression, alcohol use, and victimisation, and their association with HIV-related sexual risk among men who have sex with men and transgender women in India. Glob Public Health. 2015:12:1-16.

39. Corbin J, Morse JM. The unstructured interactive interview: Issues of reciprocity and risks when dealing with sensitive topics. Qual inquiry. 2003;9(3):335-54.

\section{Submit your next manuscript to BioMed Central and we will help you at every step:}

- We accept pre-submission inquiries

- Our selector tool helps you to find the most relevant journal

- We provide round the clock customer support

- Convenient online submission

- Thorough peer review

- Inclusion in PubMed and all major indexing services

- Maximum visibility for your research

Submit your manuscript at www.biomedcentral.com/submit

) Biomed Central 